\title{
Can a community pharmacy sleep assessment tool aid the identification of patients at risk of sleep disorders in the community: a pilot study
}

This article was published in the following Dove Press journal:

Integrated Pharmacy Research and Practice

8 November 2012

Number of times this article has been viewed

\author{
Krishneeta C Kashyap' \\ Lisa M Nissen' \\ Simon S Smith ${ }^{2}$ \\ James A Douglas ${ }^{3}$ \\ Greg J Kyle ${ }^{4}$
}

'School of Pharmacy, University of Queensland, Woolloongabba, Queensland, Australia; ${ }^{2}$ Centre for Accident Research and Road Safety, Queensland University of Technology, Kelvin Grove, Queensland, Australia;

${ }^{3}$ The Prince Charles Hospital,

Chermside, Queensland, Australia;

${ }^{4}$ School of Pharmacy, University of

Canberra, Bruce, Canberra, Australia
Correspondence: Krishneeta C Kashyap School of Pharmacy, Pharmacy Australia Centre of Excellence, The University of Queensland, 20 Cornwall St, Woolloongabba, QLD 4I02, Australia Tel +61733461744

Fax+6I 733651688

Email k.prakash@uq.edu.au
Background: When experiencing sleep problems for the first time, consumers may often approach community pharmacists for advice as they are easily accessible health care professionals in the community. In Australian community pharmacies there are no specific tools available for use by pharmacists to assist with the assessment and handling of consumers with sleep enquiries.

Objective: To assess the feasibility of improving the detection of sleep disorders within the community through the pilot of a newly developed Community Pharmacy Sleep Assessment Tool (COP-SAT).

Method: The COP-SAT was designed to incorporate elements from a number of existing, standardized, and validated clinical screening measures. The COP-SAT was trialed in four Australian community pharmacies over a 4-week period.

Key findings: A total of 241 community pharmacy consumers were assessed using the COP-SAT. A total of 74 (30.7\%) were assessed as being at risk of insomnia, $26(10.7 \%)$ were at risk of daytime sleepiness, $19(7.9 \%)$ were at risk of obstructive sleep apnea, and 121 (50.2\%) were regular snorers. A total of $116(48.1 \%)$ participants indicated that they consume caffeine before bedtime, of which $55(47 \%)$ had associated symptoms of sleep onset insomnia. Moreover, 85 (35\%) consumed alcohol before bedtime, of which 50 (58\%) experienced fragmented sleep, $50(58 \%)$ were regular snorers, and nine (10.6\%) had apnea symptoms. The COP-SAT was feasible in the community pharmacy setting. The prevalence of sleep disorders in the sampled population was high, but generally consistent with previous studies on the general population.

Conclusion: A large proportion of participants reported sleep disorder symptoms, and a link was found between the consumption of alcohol and caffeine substances at bedtime and associated symptoms. While larger studies are needed to assess the clinical properties of the tool, the results of this feasibility study have demonstrated that the COP-SAT may be a practical tool for the identification of patients at risk of developing sleep disorders in the community.

Keywords: sleep disorder, insomnia, sleep apnea, sleep assessment, pharmacy

\section{Background}

A sleep disorder is a medical illness or poor sleep behavior that leads to inadequate amounts of sleep or poor quality sleep. ${ }^{1}$ The most common sleep disorders include insomnia, snoring, and obstructive sleep apnea (OSA). ${ }^{2}$ In 2010, sleep disorders affected 1.5 million Australians and directly contributed to an estimated 818 million Australian dollars of health expenditure. ${ }^{1}$

Sleep disorders are highly prevalent in the community and are associated with significant personal and socioeconomic burden, yet they remain largely 
under-diagnosed and inadequately treated. ${ }^{3,4}$ The importance of the prevention of sleep disorders, as well as improved sleep management and assessment is becoming increasingly recognized. International estimates suggest that only one in 2000 patients with chronic insomnia consult their physicians for help, while the remainder either do nothing or resort to self-treatment with over the counter (OTC) medications, including complementary and alternative medications (CAMs) such as natural supplements, alternative therapies, and/or alcohol. ${ }^{5,6}$

In Australia, legislation regarding pharmaceutical medicines for each Australian state and territory are guided by the Federal Government's Standard for the Uniform Scheduling of Medicines and Poisons (SUSMP). ${ }^{7}$ The Standard for the Uniform Scheduling of Medicines and Poisons classifies medicines and poisons into nine schedules, of which schedules two, three, four, and eight consist of medicines for human therapeutic use. ${ }^{7}$

The term OTC refers to medicines that can be obtained without a doctor's prescription or non-prescription medicines, and includes both schedule two (pharmacy medicines) and schedule three (pharmacist only) medicines which are described below: ${ }^{8}$

- Schedule two pharmacy medicines: "Substances, the safe use of which may require advice from a pharmacist and which should be available from a pharmacy."7

- Schedule three pharmacist only medicines: "Substances, the safe use of which require professional advice but which should be available to the public from a pharmacist without a prescription."?

Specifically, when in need of sleep medicines or products to aid in alleviating sleep problems, consumers are able to purchase a variety of OTC sleep aid devices (eg, acupressure antisnore rings, antisnore nasal strips), herbal and hormonal CAMs (eg, valerian and melatonin), and sedating antihistamines (eg, doxylamine and diphenhydramine). While the sale of sleep aid devices and complementary preparations do not require the intervention of a pharmacist in Australia, sedating antihistamines are classified as schedule three medicines, and their provision requires assessment and counseling by a pharmacist. ${ }^{7}$

Community pharmacies are often the most easily accessible health care locations in the community; therefore, they are often the first point of care for individuals with self-perceived sleep problems. ${ }^{4}$ Studies have shown that pharmacists may be successfully trained to identify patients who are at risk for developing sleep disorders; ${ }^{4,9}$ however, there are currently no specific tools available for use by Australian community pharmacists to determine those at risk. An assessment device or tool must be time-efficient, cost-effective, and practical, in order to be readily incorporated into the busy community pharmacy environment. ${ }^{10}$ Questionnaires that investigate the symptoms, lifestyle factors, and underlying conditions associated with sleep disorder risk are ideal tools for this purpose. ${ }^{10,11}$

There are a variety of sleep disorder questionnaires available for diagnostic purposes. ${ }^{12,13}$ Most of these were developed by specialist sleep clinics and for use in clinic populations. ${ }^{12}$ Limited studies have trialed sleep disorder screening across international community pharmacies. ${ }^{4,9,14,15}$ Several successful feasibility trials examining sleep disorder screening have been undertaken in Australia by Fuller et al;9,14,15 however, no single, pharmacy-administered, standardized questionnaire or scale for the assessment of sleep disorder risk in the community has been nationally implemented, ${ }^{12,13,16}$ thus presenting a clinical and research gap.

The aim of this study was to assess the feasibility of improving the detection of sleep disorders within the community through the pilot of a newly developed Community Pharmacy Sleep Assessment Tool (COP-SAT). A further aim was to determine the potential contributors to the development of sleep problems with a focus on exploring the use of medications related to sleep, and any apparent links between alcohol and caffeine use and the occurrence of sleep disorder symptoms.

\section{Methods Tool development}

An extensive literature review was conducted investigating the available research in the area of sleep, sleep disorder prevalence, sleep screening tools, and community pharmacy management of sleep disorders. The COP-SAT was developed based on information found in the literature, which outlined that the most prevalent sleep disorders in Australia are insomnia, daytime sleepiness, snoring, and sleep apnea. COP-SAT questions were worded and designed accordingly, with assistance from experts in the field of sleep disorders (SS and JD). The COP-SAT consisted of 14 questions and assessed the level of risk for four major sleep disorder symptoms: insomnia, daytime sleepiness, snoring, and apneas. Two existing and validated measures with good psychometric properties, the Epworth Sleepiness Scale $(\mathrm{ESS})^{17}$ and Insomnia Severity Index (ISI) ${ }^{11}$ were modified and included as part of the tool. Questions that assessed snoring and apnea symptoms were recommended by experts SS and JD based on their practical experience with assessment 
tools, as well as with the investigation of patients in the sleep disorder clinic environment.

Questions assessing current and past prescription medication intake as well as questions on alcohol, caffeine, nicotine, marijuana, and OTC or CAM use were added to the COP-SAT to maximize its breadth as a screening tool. The researcher facilitated the process of completing the COP-SAT questions with consumers, and therefore terms such as "natural supplements" were explained and translated to the consumer at the time of implementation. The full COP-SAT is shown in Figure S1.

\section{Setting}

Four community pharmacies in suburban Brisbane, Australia were selected purposively and by convenience in an attempt to achieve variation in pharmacy and consumer demographics. The demographic details of the pharmacies are shown in Table 1. The Socioeconomic Index for Area codes are shown in Table 1 as an indication of socioeconomic status for the area in which each pharmacy was located; the higher an area's index value, the less disadvantaged that area is compared with other areas. ${ }^{18}$

\section{Feasibility of the COP-SAT process}

The feasibility of the COP-SAT surveying process was tested on the initial four consumers in the first pharmacy. It was intended that the results from these four consumers would be considered a test pilot of the COP-SAT process; however, since no issues were identified and refinement of the COP-SAT form was not needed, the results of these four consumers were included into the data analysis.

\section{Participant recruitment}

Community pharmacy consumers who were either waiting for prescriptions to be dispensed, or who were shopping in the pharmacy aisles were approached by a researcher and invited to participate in the sleep survey. The researcher approached potential participants by asking, "Would you be interested in a quick 2 to 5-minute survey while you're waiting?" Any consumer in the pharmacy was asked to participate, not only those who presented for OTC sleep requests or prescriptions. Data were collected between 9 am and 5 pm for 1 week (Monday to Friday), with no restrictions on gender or number of customers approached. Recruited participants were required to be 18 years or older. Verbal consent was obtained from all participants. Participants suffering from existing sleep conditions or any other medical conditions had these details recorded on the COP-SAT form.

\section{Data collection}

The researcher (KK) verbally asked each question and recorded participants' answers directly onto the COP-SAT form. Data from the COP-SAT forms were later scored and entered into an electronic Microsoft Access ${ }^{\circledR}$ database (Microsoft Corporation, Redmond, WA). All data were deidentified prior to data entry.

\section{Data analysis}

The risk of insomnia and daytime sleepiness scores were calculated using the recommended cut-off scores for the ISI and ESS instruments, respectively. An ESS score between 0 and 10 was considered normal; a score between 11 and 15 was considered to represent moderate daytime sleepiness risk; and a score between 16 and 24 was considered to represent an excessive daytime sleepiness risk. An ISI score between 0 and 7 was considered normal; a score between 8 and 14 suggested a subthreshold risk of insomnia; a score between 15 and 21 indicated a risk of clinically significant insomnia of moderate severity; and a score between 22 and 28 was considered to represent a risk of developing clinically severe insomnia. ${ }^{11}$ A positive risk of sleep apnea was indicated if the participant answered "yes" to all sections in question one of the COP-SAT. Question one assessed whether the participant woke up during the night with choking or suffocating symptoms, and also assessed the monthly frequency of this symptom as well as whether a partner had

Table I Sample pharmacy characteristics

\begin{tabular}{|c|c|c|c|c|c|c|c|c|}
\hline Pharmacy & $\begin{array}{l}\text { Number of } \\
\text { consumers }\end{array}$ & $\begin{array}{l}\text { Median age } \\
\text { [range] }\end{array}$ & $\begin{array}{l}\text { Gender } \\
\text { M:F }\end{array}$ & $\begin{array}{l}\text { SEIFA } \\
\text { score }\end{array}$ & Location & Chain & Independent & Type \\
\hline I & 95 & 44 [18-90] & $37: 58$ & 1062 & City & $\checkmark$ & & Shopping center \\
\hline 2 & 41 & 36 [18-85] & $12: 29$ & 1047 & City & & $\checkmark$ & Shopping center \\
\hline 3 & 48 & 48 [18-84] & $24: 24$ & 1010 & Suburban & $\checkmark$ & & $\begin{array}{l}\text { Big box } \\
\text { discounter }\end{array}$ \\
\hline 4 & 57 & 50 [20-83] & $29: 28$ & 986 & Suburban & & $\checkmark$ & Strip mall \\
\hline
\end{tabular}

Notes: Reference score for the whole of Australia = 1000; relatively lower scores indicate lower socioeconomic status. Abbreviations: M, male; F, female; SEIFA, Socioeconomic Index for Areas. 
noticed the participants exhibiting breathing problems while they slept.

Furthermore, participants were considered snorers if they answered "yes" to question two of the COP-SAT, which asked them whether they knew or had been told by a partner that they snored during sleep, and how frequent the snoring was (some nights, most nights, or every night).

\section{Statistical analysis}

All statistical analyses were performed using the Number Cruncher Statistical Software ${ }^{\mathrm{TM}}$ (NCSS, LLC, Kaysville, Utah). Univariate logistic regression was used to estimate the odds ratios (OR) of sleep disorder symptoms and their association with evening caffeine and alcohol consumption.

\section{Ethics approval}

Ethical approval was provided by the University of Queensland, School Of Pharmacy Human Research Ethics Committee (Approval number 2010/29). The owner of each pharmacy provided verbal consent for their pharmacy's participation in the data collection.

\section{Results}

A total of 241 consumers were recruited during the 1-month data collection period. The number of consumers who refused to participate was not recorded; however, the researchers noted that the common reason for refusal was that the consumers were "too busy" and "don't have time." The median age range for participants was 45 (14-90) years. In all, 102 (42.3\%) participants were male and 139 (57.7\%) were female.

A total of 74 (30.7\%) consumers reported symptoms suggestive of insomnia by conventional ISI criteria; 56 (23.2\%) were classed as being at risk for subthreshold insomnia; $14(5.9 \%)$ were at risk of moderate clinical insomnia; and four $(1.1 \%)$ were at risk of severe clinical insomnia. A total of $26(10.7 \%)$ consumers reported experiencing symptoms of daytime sleepiness as per the ESS criteria, 20 (8.3\%) were classed as being at risk of moderate daytime sleepiness, and six $(2.5 \%)$ were classed as being at risk of severe daytime sleepiness (Table 2). A total of 121 consumers reported that they were regular snorers (greater than one episode of snoring per week), and 19 reported experiencing both snoring and choking symptoms suggestive of sleep apnea.

Participants were asked to list all the medications they were consuming, including any products or substances they felt they were specifically taking to aid with sleep. Many participants were unaware that some of their medications or
Table 2 Prevalence of sleep disorder risks $(n=24$ I)

\begin{tabular}{ll}
\hline Sleep disorder risk & $\mathbf{n}(\%)$ \\
\hline Sub-threshold insomnia & $56(23.2 \%)$ \\
Moderate insomnia & $14(5.9 \%)$ \\
Severe insomnia & $4(1.1 \%)$ \\
Total at risk of insomnia & $74(30.7 \%)$ \\
Moderate daytime sleepiness & $20(8.3 \%)$ \\
Severe daytime sleepiness & $6(2.5 \%)$ \\
Total at risk of daytime sleepiness & $26(10.7 \%)$ \\
Total snorers & $121(50.2 \%)$ \\
Total at risk of sleep apnea & $19(7.9 \%)$ \\
\hline
\end{tabular}

substances affected their sleep, yet some participants listed substances that they "felt" had an effect on their sleep which actually did not (eg, paracetamol) (Table 3). A total of 55 $(22.8 \%)$ participants indicated that they regularly consumed sedating substances to aid with sleep, with seven $(2.9 \%)$ participants consuming more than one sedative agent. Seven (2.9\%) participants reported marijuana use.

Eighty-five (35\%) participants indicated that they consumed alcoholic beverages less than 5 hours prior to bedtime; however, only six (2.5\%) participants said they were consuming these alcoholic beverages specifically to aid with sleep. Of the 85 (35\%) participants who consumed alcohol less than 5 hours before bedtime, 50 (58\%) also reported experiencing fragmented sleep (sleep maintenance insomnia) $(\mathrm{OR}=1.9$ (1.1-3.3)), 50 (58\%) were regular snorers $(\mathrm{OR}=1.84$ (1.06$3.17)$ ), and nine (10.6\%) had experienced apnea symptoms $(\mathrm{OR}=0.61(0.27-1.4))$. Of the $116(48.1 \%)$ community consumers that consumed caffeine less than 5 hours prior

Table 3 Medications or substances that may affect sleep as reported by participants $(n=24 I)$

\begin{tabular}{ll}
\hline Medication/substance & $\mathbf{n}(\%)$ \\
\hline Prescription medications & $34(14 \%)$ \\
Benzodiazepines & $22(9 \%)$ \\
Non-benzodiazepine hypnotics & $5(2 \%)$ \\
Antidepressants & $2(1 \%)$ \\
Opioids & $2(1 \%)$ \\
Over the counter medications & $17(7.1 \%)$ \\
Sedating antihistamines & $9(3.7 \%)$ \\
Herbal & $3(1.2 \%)$ \\
Paracetamol & $5(2 \%)$ \\
Other/unidentified/overseas products & $4(1.7 \%)$ \\
Alcohol specifically for aid of sleep & $6(2.5 \%)$ \\
Wine & $96(39.9 \%)$ \\
Beer & $72(29.9 \%)$ \\
Spirits & $58(24.1 \%)$ \\
Coffee & $164(68 \%)$ \\
Tea & $173(71.8 \%)$ \\
Nicotine (cigarette smoking) & $37(15.4 \%)$ \\
Marijuana & $7(2.9 \%)$ \\
\hline
\end{tabular}


to bedtime, $55(47 \%)$ of them also reported experiencing associated symptoms of sleep onset insomnia ( $\mathrm{OR}=6.6$ (3.5-12.7)) (Figure 1). Of the $55(22.8 \%)$ participants who admitted to regular consumption of sedating substances, 28 reported symptoms suggestive of insomnia.

\section{Discussion}

This study found that the COP-SAT was a feasible sleep assessment tool with potential for use in community pharmacies in order to detect sleep disorder symptoms, assess sleep habits, and to determine sleep aid use among community pharmacy consumers. Further investigation will be required to validate the COP-SAT in community practice. It is important to note that in this study a researcher implemented the COP-SAT, and practicing community pharmacists or pharmacy staff members were not involved; therefore, future studies will require trial of the COP-SAT by pharmacists and pharmacy assistants in order to determine the acceptability and usability of this tool in practice. This may ultimately change or reduce the acceptability or uptake of this tool by pharmacists and pharmacy staff. Although pharmacists were not surveyed to determine their general acceptability of the COP-SAT, by allowing this research to be conducted they addressed an understanding of the importance of improved sleep management in community pharmacy.

The questions included within the COP-SAT were taken from existing validated measures for sleep (ISI and ESS), and these measures are self-administrable psychometric tools; ${ }^{11,17}$ therefore, the initial implementation of the COP-SAT would not necessarily require a pharmacist or pharmacy assistant. The COP-SAT would lend itself very readily to the idea of online or "kiosk" administration given that it may be self-administered by consumers. This may reduce time and cost burdens to the pharmacy. However, it should be noted that a pharmacist or trained pharmacy assistant would still be required to interpret the COP-SAT results and provide targeted counseling and advice to "at-risk" consumers.

Furthermore, it is important to highlight that the participants included in this study were all consumers of community pharmacies - whether attending for their cardiovascular medications, for sleep medications, or merely for purchases of cosmetics in the pharmacy - and not specifically consumers with sleep-related concerns or problems. Therefore it is of interest that the presence of sleep issues and problems in this sample were prevalent. Almost half of the participants generated responses indicative of sleep and wakefulness disorders (30.7\% insomnia, 10.7\% daytime sleepiness, 7.9\% OSA). International estimates range from $9 \%$ to $36 \%$ for insomnia, ${ }^{19} 8.7 \%$ to $20 \%$ for daytime sleepiness, ${ }^{20}$ and $2 \%$ to $10 \%$ for OSA. ${ }^{21}$ It was interesting to note that the prevalence for insomnia and OSA among the participants in this study was at the higher end of the international ranges, while daytime sleepiness was comparatively lower. Some authors suggest that this variance may be due to the fact that estimates of insomnia prevalence vary according to the diagnostic definition and criteria used. ${ }^{4,22-25}$ For example, epidemiological studies assessing the prevalence of insomnia symptoms without using restrictive criteria have reported prevalence rates of approximately $30 \%$ in the general population. ${ }^{24}$ However, studies that assessed the prevalence of insomnia symptoms when daytime consequences are taken into account reported prevalence rates of between $9 \%$ and $15 \% .^{24}$

The use of the COP-SAT may be of greater benefit in targeted consumer populations such as those attending

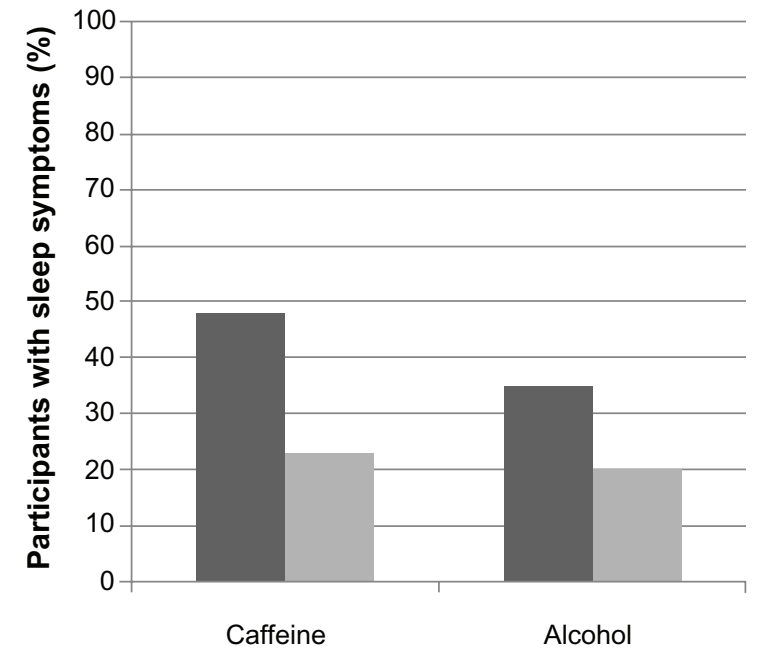

Figure I Alcohol and caffeine consumption at bedtime and associated sleep symptoms.
Consumption $\leq 5$ hours prior to bedtime

Consumption $\leq 5$ hours prior to bedtime AND associated slep symptoms 
community pharmacies with specific sleep requests or problems, and this should be considered for future studies. Currently, there are no standardized tools or surveys available for use among Australian community pharmacists in assessing consumers with sleep requests or those who attend with sleep problems. The targeted use of a sleep-specific tool such as the COP-SAT among community pharmacy consumers with sleep requests will allow for the enhanced detection of specific sleep disorder symptoms, problems, and behaviors that are contributing to sleep problems; this will ultimately lead to earlier management and increased referral of "at-risk" patients to their general practitioners.

Approximately $17 \%$ of the study participants were regularly consuming OTC sleep aids. It is not known whether these participants had been recommended an OTC sleep aid by their health care professional, or whether they were self-medicating with these products because the questions within the COP-SAT did not allow for this information to be distinguished. However, international reports indicate that approximately $28 \%$ of consumers with sleep problems self-medicate with OTC products. ${ }^{4,26}$ In 2002, Phelan et $\mathrm{al}^{27}$ investigated the use of OTC sleep aids purchased from community pharmacies in England using a self-completed questionnaire and found that many purchasers of OTC sleep aids still reported long-standing sleep problems over periods of months to years. Future modifications made to the COP-SAT tool will allow for the inclusion of questioning on self-medication.

Of the seven $(2.9 \%)$ participants who admitted to marijuana use, only two $(0.8 \%)$ were aware of the effects of marijuana on sleep patterns. Marijuana users were forthcoming about their illicit drug use when informed about the anonymity of their participation. The "kiosk"-style implementation of the COP-SAT in the future may allow users of illicit drugs to more openly report their drug use, which has implications for understanding sleep patterns and management options among these individuals.

One of the most significant findings of this study was the prevalence of caffeine and alcohol consumption prior to bedtime. As shown in Figure 1, many participants who reported caffeine or alcohol consumption within 5 hours of bedtime were also experiencing associated sleep symptoms. More specifically, a positive correlation was noted between the types of sleep symptoms: those consuming caffeine at bedtime reported experiencing symptoms of sleep onset insomnia, and those consuming alcohol at bedtime reported experiencing symptoms of both sleep maintenance insomnia and snoring. These results showed that while caffeine and alcohol intake can interfere with sleep onset and sleep quality (thus potentially contributing to sleep problems), participants may not be aware of these impacts.

Studies show that impairments in psychomotor performance are detectable in as little as 6 hours after consuming caffeine, and habitual caffeine use results in a well-established withdrawal effect of daytime sleepiness. ${ }^{28}$ Self-medicating insomnia and daytime sleepiness symptoms with substances such as caffeine and alcohol is considered a "quick relief" of symptoms for patients; however, these drugs paradoxically worsen symptoms. ${ }^{29}$ The COP-SAT allowed for the increased detection of caffeine and alcohol consumption, and for the evaluation of its link with sleep problems. Larger studies of the COP-SAT in the wider community pharmacy setting will be required to verify this effect.

The prevalence of sleep disorder symptoms found through the use of the COP-SAT indicated that many individuals in society may suffer from potential sleep problems, and that these individuals also visit community pharmacies. It is possible that these consumers may be escaping detection and treatment for their symptoms. Studies have shown that pharmacists may be successfully trained to identify patients who are at risk for developing sleep disorders, and the community pharmacy is an ideal location for assisting "at-risk" patients. ${ }^{4,14}$

Studies conducted by Tran et $\mathrm{al}^{9}$ in 2009 , and in 2011 by Fuller et $\mathrm{al}^{14}$ have investigated the use of sleep assessment tools in Australian community pharmacies. These previous studies suggested that the use of a sleep tool in a pharmacy setting is viable and feasible. ${ }^{9}$ Tran et al reported similar prevalence estimates for insomnia to those of our study (33.3\% compared to $30.7 \%$ ); however, they uncovered a much higher prevalence of OSA (21.4\% compared to $7.9 \%)$. This could be due to the different measures used for assessing OSA risk. Tran et al also found that many participants were not aware that certain medications could affect their sleep health. ${ }^{9}$ Fuller et al also suggested that extended studies in the area of sleep assessment involving community pharmacies as sites for screening should be undertaken. ${ }^{14,15}$ Therefore, implementation of the COPSAT tool by trained community pharmacists and pharmacy staff, as well as an assessment of the usability and acceptability of the COPSAT by community pharmacists and their staff would be a future implication of this study.

Methodological limitations of this study included that the number of consumers who refused to participate was 
not recorded, meaning that a response rate to the COP-SAT could not be determined, which limits the generalizability of these findings. The results were not representative of the Australian population, or the primary care population; however, the findings applied only to pharmacy clients. ${ }^{30}$ Furthermore, the pharmacies that were selected to participate were purposively chosen for convenience and demographic purposes. In addition, the questions used for the assessment of sleep apnea and snoring were not the full versions of validated tools; rather, they were items extracted from validated tools. Data were collected between 9 am and 5 pm for 1 week (Monday to Friday), and these data collection times were not varied as it was not feasible for the researcher. Therefore, the opinions of late-night and weekend shoppers have not been collected, and this may be considered a limitation. Finally, there was no exploration of consumer satisfaction with the survey, and a follow-up phase was not conducted to assess whether the identification of consumers with sleep problems led to changed behaviors or diagnoses.

\section{Conclusion}

This study demonstrates the feasibility of using a brief tool to identify those at risk of sleep disorders, and to explore the link between the use of substances such as caffeine and alcohol and sleep disorder risk. Pharmacists, as the most accessible health care professionals, can potentially play a key role in the improved management of sleep behaviors. Wider training and implementation of the COP-SAT in community pharmacies as part of a national or community management strategy could prove to be beneficial for the identification and individualized management of consumers who are "at risk" of certain sleep disorders, especially as we realize the impact of sleep disorders on public health.

\section{Disclosure}

The authors report no conflicts of interest in this work. This research did not receive any specific grants from any funding agencies in the public, commercial, or not-for-profit sectors.

\section{References}

1. Deloitte Access Economics. Reawakening Australia: The Economic Cost of Sleep Disorders in Australia, 2010. Barton, Australia: Sleep Health Australia; 2010.

2. Vgontzas AN, Kales M. Sleep and its disorders. Annu Rev Med. 1999; 50(1):387-400.

3. Oswald I. Drugs and sleep. Pharmacol Rev. 1968;20(4):273-303.

4. Hersberger KE, Renggli VP, Nirkko AC, Mathis J, Schwegler K, Bloch KE. Screening for sleep disorders in community pharmacies evaluation of a campaign in Switzerland. J Clin Pharm Ther. 2006; 31(1):35-41.
5. Omvik S, Pallesen S, Bjorvatn B, Thayer J, Nordhus IH. Night-time thoughts in high and low worriers: reaction to caffeine-induced sleeplessness. Behav Res Ther. 2007;45(4):715-727.

6. Benca RM. Diagnosis and treatment of chronic insomnia: a review. Psychiatr Serv. 2005;56(3):332-343.

7. Therapeutic Goods Administration. Poisons Standard 2011. Canberra: Commonwealth of Australia; 2011.

8. Benrimoj SI, Gilbert AL, de Almeida Neto AC, Kelly F. National implementation of standards of practice for non-prescription medicines in Australia. Pharm World Sci. 2009;31(2):230-237.

9. Tran A, Fuller JM, Wong KK, Krass I, Grunstein R, Saini B. The development of a sleep disorder screening program in Australian community pharmacies. Pharm World Sci. 2009;31(4):473-480.

10. Jackson SL, Peterson GM. Health screening in community pharmacy: an update. Australian Pharmacist. 2006;25(11):846-851.

11. Bastien $\mathrm{CH}$, Vallières A, Morin CM. Validation of the Insomnia Severity Index as an outcome measure for insomnia research. Sleep Med. 2001;2(4):297-307.

12. Douglass AB, Bornstein R, Nino-Murcia G, et al. The Sleep Disorders Questionnaire I: Creation and multivariate structure of SDQ. Sleep. 1994;17(2):160-167.

13. Spoormaker VI, Verbeek I, van den Bout J, Klip EC. Initial validation of the SLEEP-50 questionnaire. Behav Sleep Med. 2005;3(4): 227-246.

14. Fuller JM, Wong KK, Krass I, Grunstein R, Saini B. Sleep disorders screening, sleep health awareness, and patient follow-up by community pharmacists in Australia. Patient Educ Couns. 2011;83(3): 325-335.

15. Fuller J, Wong K, Krass I, Grunstein R, Saini B. The Role of Pharmacists in Sleep Health - A Screening, Awareness and Monitoring Program. Sydney: University of Sydney; 2010.

16. Roth T, Zammit G, Kushida C, et al. A new questionnaire to detect sleep disorders. Sleep Med. 2002;3(2):99-108.

17. Johns MW. A new method for measuring daytime sleepiness: the Epworth sleepiness scale. Sleep. 1991;14(6):540-555.

18. Australian Bureau of Statistics. Socio-Economic Indexes for Areas (SEIFA 2006) [webpage on the Internet]. Canberra: Australian Bureau of Statistics; 2008 [updated July 3, 2011; cited December 4, 2011]. Available from: http://www.abs.gov.au/websitedbs/D3310114.nsf/home/ Seifa_entry_page. Accessed August 13, 2012.

19. Killgore WD, Muckle AE, Grugle NL, Killgore DB, Balkin TJ. Sex differences in cognitive estimation during sleep deprivation: effects of stimulant countermeasures. Int J Neurosci. 2008;118(11): 1547-1557.

20. Calati R, Gaspar-Barba E, Cruz-Fuentes CS, et al. Excessive daytime sleepiness in depressed women. Psychiatry Res. 2010;179(2): $171-175$.

21. Finkel KJ, Searleman AC, Tymkew H, et al. Prevalence of undiagnosed obstructive sleep apnea among adult surgical patients in an academic medical center. Sleep Med. 2009;10(7):753-758.

22. U.S. Pharmacist. Pray JJ, Pray WS. The role of the pharmacist in treating insomnia. Available from: http://legacy.uspharmacist.com/index. asp?show=article\&page=8_1107.htm. Accessed August 13, 2012.

23. Morin AK, Jarvis CI, Lynch AM. Therapeutic options for sleepmaintenance and sleep-onset insomnia. Pharmacotherapy. 2007;27(1): 89-110.

24. Ohayon MM. Epidemiology of insomnia: what we know and what we still need to learn. Sleep Med Rev. 2002;6(2):97-111.

25. Schwegler K, Klaghofer R, Nirkko AC, Mathis J, Hersberger KE, Bloch KE. Sleep and wakefulness disturbances in Swiss pharmacy customers. Swiss Med Wkly. 2006;136(9-10):149-154.

26. Roth T, Roehrs T. Efficacy and safety of sleep-promoting agents. Sleep Med Clin. 2008;3(2):175-187.

27. Phelan M, Akram G, Lewis M, Blenkinsopp A, Millson D, Croft P. A community pharmacy based survey of users of over the counter sleep aids. Pharmaceutical Journal. 2002;269:287-290. 
28. James JE, Keane MA. Caffeine, sleep and wakefulness: implications of new understanding about withdrawal reversal. Hum Psychopharmacol. 2007;22(8):549-558.

29. Sin CW, Ho JS, Chung JW. Systematic review on the effectiveness of caffeine abstinence on the quality of sleep. J Clin Nurs. 2009;18(1): $13-21$.
30. Australian Bureau of Statistics. Population by age and sex, regions of Australia, 2009 [website on the Internet]. Canberra: Australian Bureau of Statistics; 2010 [updated August 3, 2011; cited November 14, 2011]. Available from: http://www.abs.gov.au/ausstats/abs@.nsf/Products/323 5.0 2009 Main+Features Main+Features?OpenDocument. Accessed January $12,2012$. 


\section{Supplementary material}

THE UNIVERSITY

COMMUNITY PHARMACY SLEEP SURVEY

Date ......... Age ........ Gender ..........

1. Do you ever wake during the night feeling like you are choking or suffocating?

$\square$ yes $\square$ no

- If yes, how many times has this happened in the last month?

$\square$ 1-2 times $\square$ 3-6 times $\square$ more than 6 times

- Has anyone ever noticed that you stop breathing when asleep? $\square$ yes $\square$ no

2. Do you snore during sleep?

$\square$ yes $\square$ no

- If yes, how often do you snore?

3. Epworth Sleepiness Scale was included here

$\square$ every night $\square$ most nights $\square$ occasional nights

4. Insomnia Severity Index was included here

5. Do you currently take anything to help you sleep at night?

${ }^{* *}$ Include non prescription, over the counter medications, natural supplements, alcohol and caffeine products. $\square$ yes $\square$ no $\quad \square$ daily $\square$ weekly $\square$ only when required

Please list:

6. Have you in the past taken anything to help you sleep at night?

${ }^{* *}$ Include non prescription, over the counter medications, natural supplements, alcohol and caffeine products. $\square$ yes $\square$ no $\quad \square$ daily $\square$ weekly $\square$ only when required

Please list:

7. Do you currently take anything to help you stay awake during the day?

**Include non prescription, over the counter medications, natural supplements, alcohol and caffeine products $\square$ yes $\square$ no $\quad \square$ daily $\square$ weekly $\square$ only when required

Please list:

8. Haveyou in the past taken anything to help you stay awake during the day?

${ }^{* *}$ Include non prescription, over the counter medications, natural supplements, alcohol and caffeine products. $\square$ yes $\square$ no $\quad \square$ daily $\square$ weekly $\square$ only when required

Please list

9. Are you a: $\square$ smoker $\square$ non-smoker $\square$ ex-smoker

10. Do you smoke: a. cigarettes $\square$ yes $\square$ no $\quad$ number ............. $\square$ daily $\square$ weekly

b. cigars $\quad \square$ yes $\square$ no $\quad$ number ............ $\square$ daily $\square$ weekly

c. tobacco $\quad \square$ yes $\square$ no $\quad$ number ............. $\square$ daily $\square$ weekly

d. marijuana $\quad \square$ yes $\square$ no $\quad$ number ............ $\square$ daily $\square$ weekly

11. Do you drink:
a. tea
$\square$ yes $\square$ no
number
$\square$ daily $\square$ weekly
b. coffee $\square$ yes $\square$ no number ...
c. wine $\square$ yes $\square$ no
number ............ $\square$ daily $\square$ weekly
d. beer? $\quad \square$ yes $\square$ no
number ............ $\square$ daily $\square$ weekly
e. spirits $\square$ yes $\square$ no
number ............ $\square$ daily $\square$ weekly

12. Do you regularly consume other food products which contain caffeine? (eg Guarana, Red Bull, cola drinks)

$\square$ yes $\square$ no $\quad$ product............. number ............. $\quad \square$ daily $\square$ weekly
product............. number ............. $\quad \square$ daily $\square$ weekly

13. What time do you drink the last tea/caffeine drink before going to bed?

14. What time do you drink the last alcoholic drink before going to bed?

Figure SI The COP-SAT.

Abbreviation: COP-SAT, Community Pharmacy Sleep Assessment Tool. 
Integrated Pharmacy Research and Practice

Dovepress

\section{Publish your work in this journal}

Integrated Pharmacy Research and Practice is an international, peer-reviewed, open access, online journal, publishing original research, reports, reviews and commentaries on all areas of academic and professional pharmacy practice. This journal aims to represent the academic output of pharmacists and pharmacy practice with particular focus on integrated care. All papers are carefully peer reviewed stimulating pharmaceutical professionals. The manuscript management system is completely online and includes a very quick and fair peer-review system, which is all easy to use. Visit http://www.dovepress.com/testimonials.php to read real quotes from published authors.

Submit your manuscript here: http://www.dovepress.com/integrated-pharmacy-research-and-practice-journal 